\title{
Discrete roles of RNA helicases in human male germline and spermatogenesis
}

\author{
Katarzyna Tutak $^{1}$ (D) Natalia Rozwadowska ${ }^{1}$ (D)
}

Received: 11 September 2019 / Revised: 7 April 2020 / Accepted: 8 April 2020 / Published online: 24 April 2020

(C) The Author(s) 2020

\begin{abstract}
RNA helicases are known from their ability to bind and unwind double-stranded RNA initiating RNA processing events. These evolutionary conserved RNA binding proteins are broadly expressed in a variety of tissues; however, we can distinguish those, which represent tissue-specific expression pattern and play unique roles in certain cell lineages. For instance, some RNA helicases mediate transcriptomic changes triggering cell differentiation which results in specification and establishment of germline in a developing embryo. Others act as safeguards responsible for maintenance of DNA integrity in germ cell. In this article, we focus on selected DEAD/DEAH-box RNA helicases involved in germline development and spermatogenesis presenting their diverse functions and implications for male fertility.
\end{abstract}

Keywords RNA helicases $\cdot$ DEAD/DEAH-box $\cdot$ Spermatogenesis $\cdot$ Infertility $\cdot$ Germline

\section{Introduction}

The large family of RNA helicases orchestrates gene expression by contributing to RNA metabolism during a whole life span of these molecules. These enzymes are classified as a vast group of highly conserved proteins characterized by their roles in rearrangement of RNA secondary structure and facilitation of RNA-protein interactions in an ATP-dependent manner. The ability of these enzymes to unwind RNA initiates cascade of posttranscriptional regulation events such as splicing, translation initiation and mRNA decay (Bourgeois et al. 2016). Additionally, to their roles in RNA metabolism, these proteins are engaged in a variety of different biochemical activities described in detail by other authors (Putnam and Jankowsky 2013). In this mini-review, we aim to focus on unique functions of selected DEAD/DEAH-box RNA helicases with an emphasis on human male germline development and spermatogenesis (Table 1, Fig. 1).

Communicated by: Michal Witt

Natalia Rozwadowska

natalia.rozwadowska@igcz.poznan.pl

1 Institute of Human Genetics, Polish Academy of Science, Strzeszynska 32, 60-479 Poznan, Poland

\section{RNA helicases: general overview}

The majority of RNA helicases belong to two main superfamilies (SF1 and SF2) comprised of subfamilies divided based on protein primary sequence variation. In humans, among SF2 group, there are two main subfamilies distinguished: the DEAD-box (DDX) helicases containing Asp-Glu-Ala-Asp (DEAD) motif represented by 42 members and DEAH-box (DHX motif: Asp-Glu-Ala-His) helicases with 16 members (Fairman-Williams et al. 2010). The most characteristic feature of RNA helicases in SF1 and SF2 families is their conserved core comprising two tandemly repeated RecA domains. These domains (named after the bacterial homologous recombination protein $\mathrm{Rec} A$ ) are responsible for nucleic acid and ATP binding and hydrolysis. Most of RNA helicases on amino or/and carboxyl termini possess an RNA or protein recognition motif which enhances the specificity of their interactors and targets. Common feature for almost all RNA helicases is the ability to bind RNA, nucleotides, ATP, and proteins. It is well described that the interplay between all these molecules affects both their conformation and function. Some helicases can also act as scaffolds for building ribonucleoprotein complexes (Putnam and Jankowsky 2013). However, one of the highly investigated and well described functions of RNA helicases is their ability to unwind RNA. Based on the catalytic mechanism, two main groups of helicases can be distinguished. One group encompasses so 
Table 1 Functions of selected RNA helicases in germ cells and spermatogenesis

\begin{tabular}{|c|c|c|c|}
\hline RNA helicase & Main molecular process & Function in germ cells/spermatogenesis & References \\
\hline DDX3Y/DBY & $\begin{array}{l}\text { Control over expression of mitotic cyclins (Drosophila) } \\
\text { Activation of germline-specific developmental genes } \\
\text { Regulation of differentiation towards germ cell lineage }\end{array}$ & $\begin{array}{l}\text { Regulation of mitotic progression (Drosophila) } \\
\text { Germ cells generation and maintenance }\end{array}$ & $\begin{array}{l}\text { Kotov et al. (2017) } \\
\text { Ramathal et al. (2015) }\end{array}$ \\
\hline DDX25/GRTH & $\begin{array}{l}\text { Formation of ribonucleoprotein complexes } \\
\text { Regulation of translation } \\
\text { Export RNAs to chromatoid bodies } \\
\text { Chromatin remodeling } \\
\text { Regulation of } T p 2 \text { transcripts }\end{array}$ & $\begin{array}{l}\text { Spermatid elongation } \\
\text { Sperm maturation }\end{array}$ & $\begin{array}{l}\text { Tsai-Morris et al. } \\
\quad(2010) \\
\text { Yang et al. (2015) } \\
\text { Kavarthapu et al. } \\
\quad(2019)\end{array}$ \\
\hline DDX4/VASA & $\begin{array}{l}\text { Regulation of expression of early and late germ cell markers } \\
\text { piRNA pathway }\end{array}$ & $\begin{array}{l}\text { Promotion of meiotic progression in human germ cells } \\
\text { Development of germline and homeostasis } \\
\text { maintenance (Drosophila) }\end{array}$ & $\begin{array}{l}\text { Medrano et al. (2012) } \\
\text { Sugimoto et al. (2009) } \\
\text { Durdevic and Ephrussi } \\
\quad(2019)\end{array}$ \\
\hline $\begin{array}{l}\text { TDRD9 } \\
\text { MOV10L1 }\end{array}$ & piRNA-mediated retrotransposon silencing & Maintenance of DNA stability in germ cells & $\begin{array}{l}\text { Wenda et al. (2017) } \\
\text { Frost et al. (2010) } \\
\text { Vourekas et al. (2015) }\end{array}$ \\
\hline
\end{tabular}

called processive RNA helicases, which mediate the unwinding of double-stranded RNA in the canonical ATP-dependent manner by binding and translocating along RNA duplexes. The second group containing DEAD-box helicases that resolve RNA duplexes in the non-processive way by local strand separation facilitated by ATP hydrolysis (Bourgeois et al. 2016; Putnam and Jankowsky 2013).

\section{Involvement of DEAD-box helicases in germ cell lineage development and spermatogenesis}

DEAD-box RNA helicases influence cell fate by contributing to RNA metabolism (Bourgeois et al. 2016). Transcriptomic changes triggered by RNA helicases initiate differentiation processes and result in a development

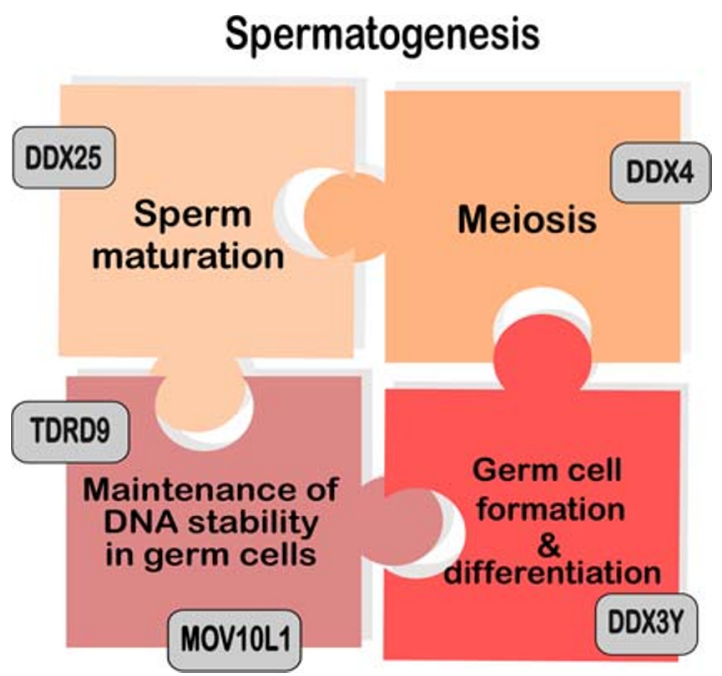

Fig. 1 Involvement of selected RNA helicases in processes leading to spermatogenesis of cell lineages (Medrano et al. 2012; Ramathal et al. 2015) Below, we describe examples of DEAD-box helicases: DDX3Y, DDX25, and DDX4/VASA in contexts of germline generation, spermatogenesis, and male infertility.

\section{DDX3Y/DBY}

Gene encoding DEAD-Box Helicase 3 Y-linked protein (DDX3Y or DBY) is located in azoospermia factor (AZF) Y-chromosomal locus which is associated with male fertility. The data presented by Kotov et al. (2017) indicates that Belle, homolog of DDX3Y in Drosophila, plays an important role in mitotic progression by controlling the expression of mitotic cyclins $A$ and $B$ in Drosophila testes. In addition, Belle regulates maintenance and cell division of germ stem cells (GSC). In humans, DDX3Y is expressed in germ cells at the premeiotic stage of spermatogenesis and mutations in this gene are associated with Sertoli cell-only (SCO) syndrome leading to azoospermia and infertility (Foresta et al. 2000). Studies performed by Ramathal et al. (2015) in a xenotransplantation model demonstrate an increased expression of germline-specific genes (PRDM14, NANOG, LIN28A) and a significant progression in differentiation of AZFa-deleted human-induced pluripotent stem cells (iPSCs) into germ cell-like cells post restoration of DDX3Y protein. Presence of DDX3Y evoked higher expression of transcriptional and translational regulator genes such as $D D X 21, S F 3 A 1, R P R D 2$, and a group of zinc-finger proteins, which might suggest an initiation of global changes in transcriptome activating germ cell differentiation. Taken together, these findings emphasize a significant contribution of DDX3Y helicase in the germ cell's fate determination. 


\section{DDX25}

DEAD-box helicase 25 (DDX25) also described as gonadotropin-regulated testicular RNA helicase (GRTH) is present in meiotic spermatocytes, round spermatids, and Leydig cells and its expression is controlled by hormonal stimulation via gonadotropin/androgen regulation. DDX25 is a multifunctional protein, which facilities several molecular events crucial for spermatogenesis completion. DDX25 binds to various mRNAs and determines their fate by forming ribonucleoprotein complexes, mediating export of transcripts from nucleus to cytoplasmic chromatoid bodies of spermatids for their further translation during spermatogenesis (TsaiMorris et al. 2010). Studies performed by Yang et al. (2015) emphasize the significance of DDX25 in male gamete formation by demonstrating that this helicase contains motif responsible for recognition of transcripts encoding transition protein 2 (Tp2) required for spermatid elongation. In addition, a newly identified mutation in $D D X 25$ gene found in azoospermic men results in phosphorylation disruption of the helicase, which interrupts chromatin remodeling and contributes to germ cells apoptosis. This finding underlines a significant influence of DDX25 protein on spermatogenesis completion (Kavarthapu et al. 2019).

\section{DDX4/VASA}

DDX4 gene also called VASA encodes DEAD-box RNA helicase 4. Homologs of this protein are present among various invertebrate and vertebrate species including C. elegans, D. melanogaster, D. rerio, X. laevis and rodents. Despite discrepancies in functions between species, this cytoplasmic protein seems to be crucial for germ cell development and fertility. In mammals, this helicase starts to be expressed in migratory primordial germ cells and continues to be present throughout gametogenesis. The highest expression is observed in spermatocytes and mature oocytes (Castrillon et al. 2000). Studies conducted by Medrano et al. (2012) indicate that ectopic expression of VASA in pluripotent stem cell lines leads to the upregulation of early (BLIMP1, GDF3, GCNF) and late germ cell markers (SCP3, ZP4, GDF9) and increases the percentage of cells positive for postmeiotic marker (ACROSIN) after differentiation towards germ cell-like cells. This leads to the conclusion that VASA plays significant role in promotion of meiotic progression in human germ cells derived from pluripotent stem cells. Studies of male patients with azoospermia or oligozoospermia imply that hypermethylation status of VASA promoter may lead to maturation arrest phenotype in testis and results in infertility (Sugimoto et al. 2009). Yu et al. (2016) analyzed semen samples from nonobstructive azoospermic (NOA) patients and indicate that noninvasive evaluation of VASA transcripts in cell-free seminal mRNAs may become more accurate way to improve identification of specific group of NOA and discrimination SCO. In conclusion, restricted expression to germinal lineage and significant involvement in germ cell development make this protein an important and vastly studied marker in contexts of infertility and spermatogenic cell differentiation.

\section{RNA helicases as safeguards of maintaining the DNA stability in germline}

Increasing number of evidences supports the statement that PIWI/piRNA pathway and its implications for transposon control are crucial for homeostasis in germline. The control over mobile genetic elements seems to be essential for successful male germline formation and production of functional gametes. For instance, recently published studies in Drosophila concerning previously mentioned RNA helicase Vasa illustrates Vasadependent transposon control. It is shown that under Vasa depletion conditions, oogenesis is not completed possibly due to upregulation of selfish genetic elements which cause DNA damage-induced oogenesis arrest (Durdevic and Ephrussi 2019). Article published by Hempfling et al. (2017) shows that among human testisbiopsies representing normal and abnormal spermatogenesis, piRNA key pathway components such as PIWIL proteins and HENMT1 (responsible for methylation of piRNA $3^{\prime}$ end) present different expression patterns. In infertile man, expression on these genes was significantly lower which resulted in elevated level of LINE-1. This indicates that disturbances in piRNA pathway abolish transposon control and may lead to spermatogenesis impairment.

\section{TDRD9}

Another example of RNA helicase involved in piRNAmediated transposon silencing is TDRD9 (Tudor domain containing 9). This protein comprises DEAH-box domain responsible for ATP-dependent RNA unwinding and Tudor domain which recognizes methylated arginine and lysine residues and mediates macromolecular complex assembly. In mice, TDRD9 helicase forms complex with MIWI2 protein which is involved in piRNA-mediated LINE-1 retrotransposons silencing. The experimental mouse model with knock-in allele comprising mutations within $T d r d 9$ ATPase motif represents male sterility, indicating the crucial role of ATPase activity of TDRD9 helicase in mice spermatogenesis (Wenda et al. 2017). Concerning human spermatogenesis, Arafat et al. (2017) analyzed samples from a group of non-obstructive azoospermic men and identified mutations resulting in frameshift and exon skipping in TDRD9 transcripts. Authors 
claimed that presented mutations were responsible for maturation arrest which led to infertility.

\section{MOV10L1}

MOV10L1 (Mov10 like RISC complex RNA helicase) is involved in genetic stability maintenance in germ cells. In mice, homologous protein is shown to be a key regulator of piRNAdirected LINE-1 retrotransposon silencing in male germline (Frost et al. 2010). In humans, the underlying mechanism of this regulation was presented by Vourekas et al. (2015) showing that MOV10L1 specifically binds to piRNA precursors, which initiates their processing. Subsequently, piRNA intermediate fragments are loaded to PIWI proteins, which lead to the suppression of retrotransposon activation. RNA helicase MOV10L1 is abundant in testis, and its expression begins in prenatal gonocytes and ends in postmeiotic spermatids. In addition, single-nucleotide polymorphisms in MOV10L1 gene were identified in infertile men and associated with spermatocyte maturation arrest resulting in azoospermia (Sarkardeh et al. 2014).

\section{Conclusions}

RNA helicases are evolutionary conserved proteins present in a broad range of species. Growing number of evidence emphasizes the fact that the role of these proteins in developmental processes is crucial. RNA helicases play distinct roles in promoting germline establishment and maintenance and gametogenesis. They act as safeguards of germline DNA stability and influence changes in transcriptome by contributing to meiotic progression and sperm maturation. Importance of these proteins is supported by data indicating that several mutations in RNA helicases genes are associated with male infertility. Relevance in spermatogenesis combined with mutations occurrence among male population implies that RNA helicases may serve as potential genetic markers improving diagnostics of infertile men. Despite the demonstrated significance in male gamete formation, the exact mechanisms, functions, and pathways involving RNA helicases remain to be elucidated and demand further investigation.

Funding information The authors disclosed receipt of the following financial support for the authorship and/or publication of this article: The study was supported by the National Science Centre, Poland, grant number 2017/25/B/NZ5/01231.

\section{Compliance with ethical standards}

Conflict of interests The authors declare that they have no conflicts of interest.
Open Access This article is licensed under a Creative Commons Attribution 4.0 International License, which permits use, sharing, adaptation, distribution and reproduction in any medium or format, as long as you give appropriate credit to the original author(s) and the source, provide a link to the Creative Commons licence, and indicate if changes were made. The images or other third party material in this article are included in the article's Creative Commons licence, unless indicated otherwise in a credit line to the material. If material is not included in the article's Creative Commons licence and your intended use is not permitted by statutory regulation or exceeds the permitted use, you will need to obtain permission directly from the copyright holder. To view a copy of this licence, visit http://creativecommons.org/licenses/by/4.0/.

\section{References}

Arafat M, Har-Vardi I, Harlev A et al (2017) Mutation in TDRD9 causes non-obstructive azoospermia in infertile men. J Med Genet 54:633639. https://doi.org/10.1136/jmedgenet-2017-104514

Bourgeois CF, Mortreux F, Auboeuf D (2016) The multiple functions of RNA helicases as drivers and regulators of gene expression. Nat Rev Mol Cell Biol 17:426-438. https://doi.org/10.1038/nrm.2016.50

Castrillon DH, Quade BJ, Wang TY et al (2000) The human VASA gene is specifically expressed in the germ cell lineage. Proc Natl Acad Sci U S A 97:9585-9590. https://doi.org/10.1073/pnas.160274797

Durdevic Z, Ephrussi A (2019) Germ cell lineage homeostasis in drosophila requires the vasa RNA helicase. Genetics 213:911-922. https://doi.org/10.1534/genetics.119.302558

Fairman-Williams ME, Guenther U-P, Jankowsky E (2010) SF1 and SF2 helicases: family matters. Curr Opin Struct Biol 20:313-324. https:// doi.org/10.1016/j.sbi.2010.03.011

Foresta C, Ferlin A, Moro E (2000) Deletion and expression analysis of AZFa genes on the human $Y$ chromosome revealed a major role for DBY in male infertility. Hum Mol Genet 9:1161-1169. https://doi. org $/ 10.1093 / \mathrm{hmg} / 9.8 .1161$

Frost RJA, Hamra FK, Richardson JA et al (2010) MOV10L1 is necessary for protection of spermatocytes against retrotransposons by Piwi-interacting RNAs. Proc Natl Acad Sci 107:11847-11852. https://doi.org/10.1073/pnas.1007158107

Hempfling AL, Lim SL, Adelson DL et al (2017) Expression patterns of HENMT1 and PIWIL1 in human testis: implications for transposon expression. Reproduction 154:363-374. https://doi.org/10.1530/ REP-16-0586

Kavarthapu R, Anbazhagan R, Raju M et al (2019) Targeted knock-in mice with a human mutation in GRTH/DDX25 reveals the essential role of phosphorylated GRTH in spermatid development during spermatogenesis. Hum Mol Genet 28:2561-2572. https://doi.org/ 10.1093/hmg/ddz079

Kotov AA, Olenkina OM, Godneeva BK et al (2017) Progress in understanding the molecular functions of DDX3Y (DBY) in male germ cell development and maintenance. Biosci Trends 11:46-53. https:// doi.org/10.5582/bst.2016.01216

Medrano JV, Ramathal C, Nguyen HN et al (2012) Divergent RNAbinding proteins, DAZL and VASA, induce meiotic progression in human germ cells derived in vitro. Stem Cells 30:441-451. https:// doi.org/10.1002/stem.1012

Putnam AA, Jankowsky E (2013) DEAD-box helicases as integrators of RNA, nucleotide and protein binding. Biochim Biophys Acta - Gene Regul Mech 1829:884-893. https://doi.org/10.1016/j.bbagrm.2013. 02.002

Ramathal C, Angulo B, Sukhwani M et al (2015) DDX3Y gene rescue of a Y chromosome AZFa deletion restores germ cell formation and 
transcriptional programs. Sci Rep 5:15041. https://doi.org/10.1038/ srep15041

Sarkardeh H, Totonchi M, Asadpour O et al (2014) Association of MOV10L1 gene polymorphisms and male infertility in azoospermic men with complete maturation arrest. J Assist Reprod Genet 31:865. https://doi.org/10.1007/S10815-014-0240-1

Sugimoto K, Koh E, Sin H-S et al (2009) Tissue-specific differentially methylated regions of the human VASA gene are potentially associated with maturation arrest phenotype in the testis. J Hum Genet 54:450-456. https://doi.org/10.1038/jhg.2009.59

Tsai-Morris C-H, Sheng Y, Gutti RK et al (2010) Gonadotropin-regulated testicular RNA helicase (GRTH/DDX25): a multifunctional protein essential for spermatogenesis. J Androl 31:45-52. https://doi.org/10. 2164/jandrol.109.008219

Vourekas A, Zheng K, Fu Q et al (2015) The RNA helicase MOV10L1 binds piRNA precursors to initiate piRNA processing. Genes Dev 29:617-629. https://doi.org/10.1101/gad.254631.114
Wenda JM, Homolka D, Yang Z et al (2017) Distinct roles of RNA helicases MVH and TDRD9 in PIWI slicing-triggered mammalian piRNA biogenesis and function. Dev cell 41:623-637.e9. https:// doi.org/10.1016/j.devcel.2017.05.021

Yang R, Tsai-Morris C-H, Kang JH, Dufau ML (2015) Elucidation of RNA binding regions of gonadotropin-regulated testicular RNA helicase (GRTH/DDX25) to transcripts of a chromatin remodeling protein essential for spermatogenesis. Horm Mol Biol Clin Investig 22:119-130. https://doi.org/10.1515/hmbci-2015-0004

Yu Q, Gu X, Shang X et al (2016) Discrimination and characterization of Sertoli cell-only syndrome in non-obstructive azoospermia using cell-free seminal DDX4. Reprod BioMed Online 33:189-196. https://doi.org/10.1016/j.rbmo.2016.05.001

Publisher's note Springer Nature remains neutral with regard to jurisdictional claims in published maps and institutional affiliations. 